\title{
Mulheres curdas sob a perspectiva cinematográfica: uma discussão sobre o filme Filhas do Sol
}

\author{
Kurdish women from a cinematographic perspective: a discussion \\ about the film Girls of the Sun
}

\section{Mujeres kurdas desde una perspectiva cinematográfica: una discusión sobre la película Las Hijas del Sol}

Jamer Guterres de MELLO ${ }^{1}$ Juliana Santoros MIRANDA² Maria Ignês Carlos MAGNO3

\section{Resumo}

Este artigo levanta uma discussão sobre o filme Filhas do Sol (2018), dirigido pela cineasta francesa Eva Husson, considerando as representações do povo curdo e suas lutas, sobretudo a resistência feminina ao Estado Islâmico. O objetivo é avaliar de que forma o filme estabelece e apresenta a situação curda - na oposição Ocidente/Oriente - em relação à representatividade feminina, principalmente como uma nova forma de retratar conflitos armados em produções audiovisuais e, também, no trabalho de cobertura jornalística, uma vez que, em geral, a questão curda é pouco pautada no Ocidente devido à distância geográfica e às diferenças culturais. Tomamos os elementos narrativos do filme enquanto materiais discursivos de grande relevância estética e política ao produzirem discursos que, muitas vezes, parecem distantes do espectador, mesmo sendo uma narrativa ficcional baseada em acontecimentos reais. Para tanto, utilizamos referenciais teóricos que fundamentam alguns conceitos pertinentes a tal discussão, como orientalismo, representações sociais, identidade

\footnotetext{
${ }^{1}$ Docente no Programa de Pós-Graduação em Comunicação da Universidade Anhembi Morumbi (PPGCOM-UAM), doutor em Comunicação pela Universidade Federal do Rio Grande do Sul (PPGCOMUFRGS). E-mail: jamermello@gmail.com. ORCID: https://orcid.org/oooo-0003-1771-204X.

2 Mestranda no Programa de Pós-Graduação em Comunicação da Universidade Anhembi Morumbi (PPGCOM-UAM), graduada em Jornalismo pela Universidade Anhembi Morumbi (UAM). E-mail: julianasantorosmestrado@gmail.com. ORCID: https://orcid.org/oooo-ooo1-8656-4875.

3 Docente no Programa de Pós-Graduação em Comunicação da Universidade Anhembi Morumbi (PPGCOM-UAM), doutora em Ciências da Comunicação pela Escola de Comunicações e Artes da Universidade de São Paulo (ECA-USP). E-mail: unsigster@gmail.com. ORCID: 000o-0003-1520-9256.
} 
cultural, discurso, além da contextualização geopolítica e social do Curdistão e seus territórios relacionados.

Palavras-chave: Cinema; feminismo; orientalismo; Curdistão; Filhas do Sol.

\begin{abstract}
This article discusses the film Girls of the Sun (2018), directed by the French filmmaker Eva Husson, considering the representations of the Kurdish people and their struggles, especially the female resistance to the Islamic State. The objective is to evaluate how the film establishes and presents the Kurdish situation - in the West/East opposition in relation to female representation, mainly as a new way of portraying armed conflicts in audiovisual productions and, also, in the work of journalistic coverage, since, in general, the Kurdish question is not very important in the West due to geographical distance and cultural differences. We take the narrative elements of the film as discursive materials of great aesthetic and political relevance when producing speeches that often seem distant from the viewer, even though it is a fictional narrative based on real events. For that, we use theoretical references that support some concepts pertinent to such discussion, such as Orientalism, social representations, cultural identity, discourse, in addition to the geopolitical and social contextualization of Kurdistan and related territories.
\end{abstract}

Keywords: Cinema; feminism; orientalism; Kurdistan; Girls of the Sun.

\title{
Resumen
}

Este texto plantea una discusión sobre la película Las Hijas del Sol (2018), dirigida por la cineasta francesa Eva Husson, considerando las representaciones del pueblo kurdo y sus luchas, especialmente la resistencia femenina al Estado Islámico. El objetivo es evaluar cómo la película establece y presenta la situación kurda - en una oposición Oriente/Occidente - en relación con la representación femenina, principalmente como una nueva forma de retratar los conflictos armados en las producciones audiovisuales y, también, en el trabajo de cobertura periodística, ya que, en general, el tema kurdo no se discute mucho en el occidente debido a la distancia geográfica y las diferencias culturales. Tomamos los elementos narrativos de la película como materiales discursivos de gran relevancia estética y política a la hora de producir discursos que muchas veces parecen distantes del espectador, aunque se trata de una narrativa de ficción basada en hechos reales. Por lo tanto, utilizamos referencias teóricas que sustentan algunos conceptos relevantes para esta discusión, como el orientalismo, las representaciones sociales, la identidad cultural, el discurso, además de la contextualización geopolítica y social del Kurdistán y sus territorios relacionados.

Palabras clave: Cine; feminismo; orientalismo; Kurdistán; Las Hijas del Sol. 


\section{Introdução}

Curdistão, Partido dos Trabalhadores do Curdistão (PKK), Unidade de Defesa Feminina Curda (YPJ), combate direto de mulheres ao Estado Islâmico e confederalismo democrático não são temas recorrentes em produções audiovisuais e cinematográficas difundidas entre o público ocidental, principalmente o público brasileiro. Tal assunto é pouco pautado devido à distância geográfica e às diferenças culturais e, quando citado, possivelmente gera muitas dúvidas e distorções, a depender do tipo de abordagem utilizada em sua disseminação.

Dada tal conjuntura, filmes como Filhas do Sol, da diretora francesa Eva Husson, lançado em 2018 (com sete indicações a diferentes prêmios no Festival de Cannes), alcançam um feito de maior abrangência, ultrapassando um caráter de mero produto de entretenimento audiovisual. É possível tomar os elementos narrativos de produções como esta enquanto materiais discursivos de grande relevância estética e política ao produzirem discursos que, muitas vezes, parecem distantes do espectador, mesmo sendo uma narrativa ficcional baseada em acontecimentos reais.

Filhas do Sol é um drama em moldes hollywoodianos que trata de um dos episódios mais importantes de luta das mulheres curdas na região do Iraque, um tema pouco debatido no Ocidente, o que motiva a interpretação acerca de determinados aspectos do filme (em essência, melodramático). A obra foi indicada a diversos prêmios do Festival de Cannes, entre eles: a Palma de Ouro, o Prêmio do Júri, o Prêmio de interpretação feminina, o Prêmio de interpretação masculina, o Prêmio de Roteiro, o Prêmio de melhor diretor e o Grand Pix.

Embora desperte reflexões acerca de determinadas escolhas aplicadas na obra, como a linguagem melodramática (sobretudo na trilha sonora), Filhas do Sol desempenha o seu papel de tornar acessível um tema como o retratado, mesmo de forma ficcional. Sendo assim, penetra com mais facilidade em seu público-alvo ocidental, ainda que não seja uma obra com fins diretamente didáticos, embora indique: "baseado em fatos reais".

Buscamos avaliar como a situação das mulheres do Curdistão, a relação Ocidente/Oriente, a representatividade feminina em diversos âmbitos como a maternidade, a luta armada e a quebra de estereótipo dos soldados de guerra masculinos em produções audiovisuais e até mesmo o trabalho jornalístico desempenhado por mulheres em tais regiões de conflitos foram representados no filme em questão. 
Nesse sentido, é importante retomar conceitos relacionados aos temas explorados no filme, de acordo com referencial teórico específico para discutir cultura nacional e identidade cultural, representações sociais, exotização e etnização do nãoeuropeu e as narrativas de alteridade. Entre o referencial também se encontram estudos anteriores e a discussão sobre estereótipos, além de uma contextualização sobre os fatos sociopolíticos retratados para que a discussão sobre o filme seja compreensível.

\section{Contexto histórico, social e geopolítico do Curdistão}

O Curdistão não é um país com fronteiras delimitadas, mas uma região montanhosa que abarca parte da Turquia, do Irã, da Síria e do Iraque, além de Armênia e Azerbaijão, onde vive o povo curdo. Este também se encontra em diversos países que não fazem parte do Oriente Médio, como Rússia e Alemanha, nos quais chegam a aproximadamente 1 milhão de pessoas; ou Israel, França e Suécia, sendo que, no caso destes, estima-se que sejam em 100 mil por território, situação denominada "diáspora curda" (FIGUEIREDO, 2014).

\section{Figura 1: Mapa da região do Curdistão}

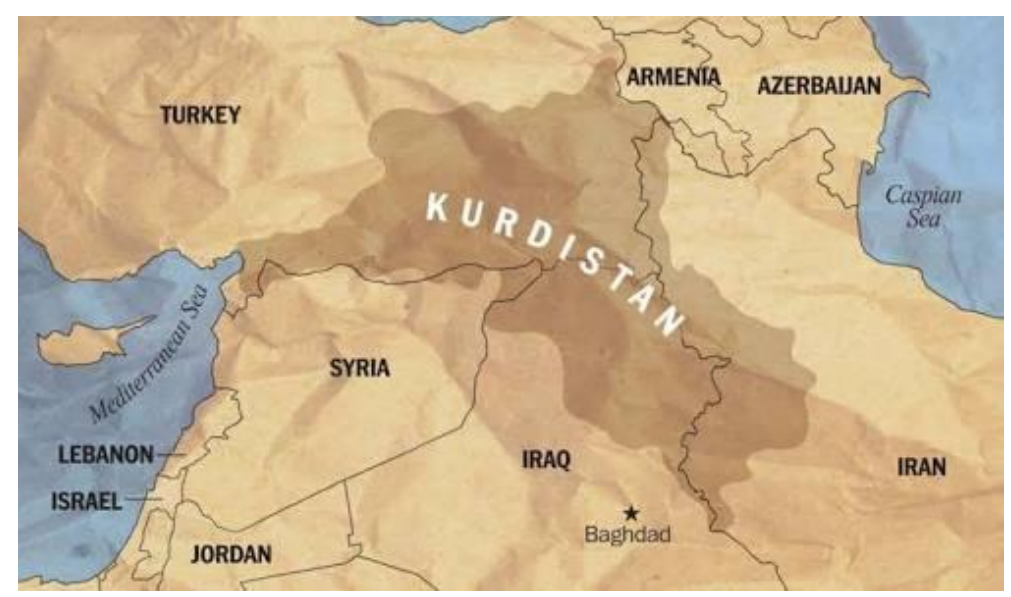

Fonte: BBC (2019)

Os curdos são um grupo étnico diverso de aproximadamente 36 milhões de pessoas (NAVARRO, 2018) e, atualmente, são considerados "a maior nação sem Estado do mundo" (VÁZQUEZ, 2017, p. 35). Possuem um idioma próprio (com diversos dialetos), porém, são proibidos de praticá-lo em diversos países. Sobre essa 
questão da língua, diretamente ligada à política, Kelen Pessuto afirma, em sua tese, que:

A construção da identidade de uma nação está vinculada à língua deste povo, que se torna um instrumento de poder. A ideia de nação curda está diretamente ligada à questão do idioma curdo. Os governos soberanos, sabendo da importância do curdo como mobilizador de identidades acabam por coibir seu uso. O processo de assimilação perpetrado pelas "nações hospedeiras" (categoria nativa) - Irã, Iraque, Síria e Turquia - começa já pela língua, pois ao minar a cultura de um povo, enfraquece-se sua memória coletiva (PESSUTO, 2017, p. 82).

Ao contrário de muitos povos do Oriente Médio, os curdos não são árabes, mas iranianos, ligados aos persas4. A maioria curda pratica a religião islâmica, embora também existam judeus, cristãos e praticantes de outras religiões na comunidade, como os yazidis, que "reúnem preceitos do zoroastrismo dos persas, do sufismo, ramo místico do islamismo e do cristianismo" (MELLO, 2017, p. 171). Os yazidis, ao longo da história, foram vítimas de diversas opressões, sendo ainda presente a perseguição do Estado Islâmico, situação também retratada no filme Filhas do Sol.

Os curdos têm conseguido manter sua cultura, língua e tradições de geração a geração e, hoje, pela forma com que se organizam politicamente, sobretudo nas regiões de Cobane e Rojava: por meio do confederalismo democrático (sistema estabelecido em algumas regiões curdas). Proposto pelo fundador e líder do Partido dos Trabalhadores do Curdistão (PKK, na Turquia) Abdullah Öcalan, o confederalismo democrático "é um modelo social, político e econômico de autoadministração de diferentes povos, liderado pelas mulheres e pela juventude” (DIRIK, 2017, p. 19). Possui como pilares o anticapitalismo, o antipatriarcado e a ecologia, funcionando como uma democracia sem Estado, por meio de comunas. A ativista curda Dilar Dirik explica:

A comuna é uma vizinhança conscientemente auto-organizada e constitui o mais essencial e radical aspecto da prática democrática. Possui comitês trabalhando em diferentes questões, como paz e justiça, economia, segurança, educação, mulheres, juventude e serviços sociais (DIRIK, 2017, p. 19).

\footnotetext{
4 Entre as diversas etnias da região, estão a árabe e a persa. Os árabes são o maior grupo étnico do Oriente Médio, o que leva à generalização do Ocidente sobre tais diferenças. Porém, também há os povos iranianos, muitos deles descendentes dos persas, cuja língua é de origem indo-europeia. Os persas descendem dos povos indo-europeus, que migraram pela Âsia Central e chegaram à região do Irã por volta de 1000 a.C. Já o povo árabe é originário da península Arábica (FIGUEIREDO, 2014, s/p).
} 
O Curdistão do território sírio (na região nordeste do país) é denominado Rojava (COMITÊ, 2017). Na Síria, os grupos guerrilheiros curdos são o YPG e o YPJ, associados ao Partido de União Democrática (PYD). As Unidades de Defesa Popular (YPG) são as milícias de Rojava encarregadas de defender a região, criadas em 2004, mas que vieram a público em 2011, formadas principalmente por soldados homens. Já as Unidades de Defesa das Mulheres (YPJ) são as milícias das mulheres de Rojava, criadas somente em 2013, de formação exclusivamente feminina (COMITÊ, 2017). Combatentes curdos da YPG ou da YPJ são denominadas(os) peshmerga, cujo significado é literalmente "aquele que enfrenta a morte" (MELLO, 2017, p. 169). Tal expressão é adotada no filme Filhas do Sol.

De acordo com Pessuto (2017), muitos papéis de liderança na sociedade curda já ficavam a cargo das mulheres, mas a partir da criação da YPJ, "criou-se uma estrutura feminina própria, com suas próprias demandas" (PESSUTO, 2017, p. 135).

Os grupos e ações ligados ao PKK e ao PYD são nomeados como terroristas por diversos países. Entre eles, alguns pertencentes à União Europeia, Estados Unidos e a própria Turquia. Entretanto, o filósofo, crítico cultural, pesquisador e intelectual marxista esloveno Slavoj Žižek fala sobre a atuação e aspirações das organizações curdas:

Não seria bom dar aos curdos uma chance de governarem a si mesmos? Sabemos que é uma utopia! Até hoje os curdos só se defenderam. Eles nunca tiveram uma inclinação imperialista, agressiva. Eles nunca mataram os outros. Dar aos curdos a chance de autogoverno significa estabilidade para a região. Os curdos são o grupo mais secular no Oriente Médio. Reconhecer o autogoverno aos curdos significa apoiar a paz (ŽIŽEK, 2015).

É notável a atuação dos curdos no combate ao Estado Islâmico (também denominado Daesh ou ISIS), sobretudo pela YPJ, fato coerentemente retratado na obra Filhas do Sol. E é justamente o evento contextualizado a seguir por Patrícia Campos Mello que será visto no filme (entre outros):

A YPJ teve papel fundamental no resgate das mulheres yazidis escravizadas pelo Estado Islâmico na região iraquiana de Sinjar em agosto de 2014. As soldadas sabiam que, se fossem capturadas pelos homens do Daesh, seriam estupradas e mortas. Por isso, muitas faziam ataques suicidas quando se viam perto de ser capturadas. Em Sinjar e nas batalhas para libertar cidades sírias como Kobane e Tell Abyad, as 
soldadas da YPJ tinham consciência de que lutavam para evitar anos de retrocesso (MELLO, 2017, p. 135).

As medidas adotadas pelo Estado Islâmico são norteadas pela ideologia do grupo, que é definido como organização jihadista e wahabita e que:

(...) Surgiu no bojo da tragédia humanitária causada pela intervenção norte-americana no Iraque, logo se espalhando para a Síria quando da guerra civil local - mais precisamente quando o choque inicial entre as forças pró-Assad e Ocidente levou a uma destruição mútua, a qual ainda puniu severamente a população civil que, desamparada, se tornou presa fácil para o discurso extremista. Tem por objetivo criar um califado no Oriente Médio (COMITÊ, 2017, p. 9).

Como o próprio filme mostra, a YPJ é um dos grupos que mais combatem o Estado Islâmico (ao lado da YPG). As mulheres são especialmente temidas: os fundamentalistas acreditam que, ao serem mortos por uma mulher, não vão para o Paraíso (MELLO, 2017), uma crença explicada durante a narrativa pela personagem Bahar (interpretada por Golshifteh Farahani).

\section{Representações sociais: discursos de alteridade, orientalismo e eurocentrismo}

Textos, vídeos, filmes, podcasts, imagens e outros meios de transmitir, interpretar ou criar linguagem e conteúdo como um todo, fazem parte de um processo disseminador de discursos, conforme conceituado por Michel Foucault (1996). Para o autor, o discurso é o fator-chave das representações, já que dependendo do que inclui ou exclui, transmite presença ou ausência de poder para o seu objeto retratado (FOUCAULT, 1996).

Tais discursos, sobretudo quando se tratam de um evento distante, são transmitidos e exercidos por meio de uma tradução compreensível para o público final, arraigada à criação das representações sociais. Mesmo buscando o maior detalhamento possível, simbolizar histórias reais de vida e de um povo mostra-se uma tarefa complexa, sobretudo pelo viés ocidental (quando o assunto em questão é relacionado ao Oriente), trazendo a ideia de alteridade, que trata da narrativa do outro e do distante.

Eni Orlandi (1990) complementa o conceito de discurso e sua relação com a ideologia ocidental, colonização e a figura do exótico: 


\begin{abstract}
A ideologia tem, pois, uma materialidade e o discurso é o lugar em que se pode ter acesso a essa materialidade. Conhecer o seu funcionamento é saber se o discurso colonial continua produzindo os seus sentidos, desde que se apresentem as condições. E um dos seus efeitos - que não é o menor - é o que chamo a "perversidade do político". Isto é, no imaginário construído por essas práticas de linguagem, as relações de colonização aparecem não em seu lugar próprio, mas sim como reflexo indireto. Isto acontece sempre que um discurso se faz passar por outro discurso. Nesse caso, se apaga o discurso histórico e se produz um discurso sobre a cultura. Como efeito desse apagamento, a cultura resulta em "exotismo". (ORLANDI, 1990, p. 16)
\end{abstract}

Ao ter contato com um material que trata de uma região afastada geograficamente, seu consumidor forma determinada visão sobre o assunto em questão a partir deste conteúdo, portanto, neste momento marca sua relação entre $o$ eu e o outro, construindo o conceito de alteridade, como diz Lobato (2015). Este processo é encarregado de transmitir as identidades socioculturais que o espectador (ou leitor) não conhece, o que remete, no caso deste estudo, ao orientalismo, de Edward Said (1990).

Antes mesmo de detalhar o referencial de Said, é interessante pontuar o que diz o filósofo Slavoj Žižek, a fim de interligar o caso específico do povo curdo à posição orientalista do Ocidente:

Vamos olhar para a história: os curdos são as maiores vítimas da separação colonial. A abordagem dos ocidentais para o Oriente Médio é baseada em qual tribo vai lutar contra qual. Em outras palavras, o Ocidente decide sobre isso. Há uma tradição de intervenção ocidental no Oriente Médio (ŽIŽEK, 2015, s/p).

Essa tradição exposta por Žižek (2015) não é por acaso. Inclusive, manifesta posições de poder (neste caso, o “eurocentrismo”), sendo essas já explicadas por Edward Said, que define orientalismo como:

(...) Um modo de resolver o Oriente que está baseado no lugar especial ocupado pelo Oriente na experiência ocidental europeia. O Oriente não está apenas adjacente à Europa; é também onde estão localizadas as maiores, mais ricas e mais antigas colônias europeias, a fonte das suas civilizações e línguas, seu concorrente cultural e uma das suas mais profundas e recorrentes imagens do Outro. Além disso, o Oriente ajudou a definir a Europa (ou o Ocidente), como sua imagem, ideia, personalidade e experiência de contraste. Contudo, nada desse Oriente é meramente imaginativo. O Oriente é parte integrante da civilização e 
da cultura materiais da Europa. O Oriente expressa e representa esse papel, cultural e até mesmo ideologicamente, como um modo de discurso com o apoio de instituições, vocabulário, erudição, imagística, doutrina e até burocracias e estilos coloniais (SAID, 1990, p. 13-14).

Said (1990) e Santos (2013) se complementam, sobretudo quando o segundo afirma que as narrativas de viajantes no geral, ao longo da História, foram as responsáveis pela "formação discursiva neocolonial que escreve e inscreve o Outro, sujeitando-o em sua posição de subordinação: o primitivo, o selvagem, o nativo, o exótico" (SANTOS, 2013, p. 1, grifo do autor).

Ainda sobre a visão orientalista, pontua-se a questão de generalização da cultura oriental, como já apresentado em estudos anteriores:

Um fato a se observar sobre o orientalismo é a postura de homogeneização do Ocidente em relação ao Oriente. Este, muitas vezes, é visto e retratado como "um só", excluindo-se sua diversidade de identidades e culturas. Afinal, de acordo com o discurso hegemônico, tudo o que não faz parte do Ocidente pertence ao mundo de lá, sendo este representado por um caráter simplista e destoante em relação à sua diversidade cultural, religiosa, social e étnica (MIRANDA, 2018b, p. 21).

Tal postura da homogeneização é notada no fato de que, muitas vezes, os simbolismos mais marcantes estabelecidos em relação ao Oriente Médio são aqueles referentes à religião islâmica, o fundamentalismo religioso, ataques terroristas, a Guerra na Síria e a questão de Israel e Palestina, mesmo que, em termos de números, os curdos não sejam uma minoria.

Samir Amin (2021, p. 70), economista marxista franco-egípcio, afirma que "o mundo afro-asiático é por excelência o universo não ocidental, não cristão". Entretanto, “(...) é um universo também diversificado nas suas raízes, confucionistataoísta, budista hinduísta, islâmico, animista”, embora tal diversificação não seja completamente compreendida no Ocidente (ou não desejada).

Sendo assim, Amin explica que o eurocentrismo está diretamente ligado ao surgimento do sistema capitalista e à ideologia que este mesmo sistema impõe no mundo moderno. E esta é a raiz da questão do povo curdo e o seu não reconhecimento oficial enquanto povo: 
O eurocentrismo é um culturalismo: ele supõe a existência de invariantes culturais que conformam os trajetos históricos dos diferentes povos, irredutíveis entre si. É, então, anti-universalista, porque não se interessa em descobrir eventuais leis gerais da evolução humana. Mas apresenta-se como um universalismo, uma vez que propõe a todos a imitação do modelo ocidental como única solução aos desafios do nosso tempo (AMIN, 2021, p. 11).

Este paradigma, baseado em evidências aparentes e na manutenção do senso comum, funciona de modo espontâneo e, por isso, "se manifesta de diversas maneiras, tanto na expressão dos preconceitos trivializados pelos meios de comunicação como nas frases eruditas dos especialistas de diversos domínios da ciência social”, segundo Amin (2021, p. 12).

Ainda de acordo com o autor, para a categoria dominante (países da Europa e/ou hegemônicos), o lema se apresenta como "imitai o Ocidente, que é o maior dos mundos”, construção mítica que se coloca em um mundo dividido em centro/periferia. Tal contraste, resultante da expansão mundial do capitalismo "realmente existente", define-se em termos econômicos e ideológicos: "de um lado as sociedades capitalistas acabadas, dominantes; do outro, as sociedades capitalistas atrasadas, inacabadas e dominadas" (2021, p. 12).

Uma dúvida pode surgir quanto à nomenclatura do eurocentrismo: por que é baseada exclusivamente na Europa, embora os Estados Unidos sejam a maior potência do mundo? Amin se antecipa e explica que, hoje, este centro mundial "é a Europa Ocidental, a América do Norte, o Japão e alguns outros estados (Austrália, Nova Zelândia, Israel), em oposição às periferias (América Latina e Antilhas, África e Ásia não comunista, excetuando o Japão)" (2021, p. 17). Ainda que o próprio "centro dos centros" seja norte-americano:

Não obstante, supondo que substituíssemos o termo de eurocentrismo
pelo de ocidental-centrismo (aceitando a definição comum do termo
Ocidente), perderíamos de vista casos como a América Latina ou o
Japão, negando a importância que devemos atribuir à origem
europeia da cultura capitalista. Pensando bem, "eurocentrismo"
expressa bem o que quer dizer (AMIN, 2021, p. 17, grifo nosso).

Nutrido pelo neoliberalismo, cuja resposta a tudo reafirma e legitima "os preconceitos, o que explica sem dúvida o seu êxito" (2021, p. 14), este mundo novo imposto originalmente pela Europa "põe-nos sistematicamente a serviço do desenvolvimento das forças produtivas, da formação de uma sociedade laica, 
portadora, num futuro, da aspiração democrática". E por meio desta democracia neoliberal, os países hegemônicos "tomam consciência do alcance universal de suas civilizações" (2021, p. 79), legitimando os seus projetos políticos mundiais.

\section{Cultura, identidade e estereótipo}

Dada a contextualização histórico-política da opressão ocidental sobre a população curda, é preciso pontuar a questão da cultura, cujo "princípio talvez mais forte de constituição do discurso colonial, que é o produto mais eficaz do discurso das descobertas, é reconhecer apenas o cultural e desconhecer (apagar) o histórico, o político" (ORLANDI, 1990, p. 15), como se a própria cultura e sua relação com a política, principalmente com a ideia de nação, pudesse ser completamente segregada.

Stuart Hall (2005) e Kathryn Woodward (2000) convergem nos estudos sobre cultura e identidade, sobretudo com exemplos a respeito de nacionalidades, fator relevante para o presente estudo, no qual se discute um filme de uma diretora francesa sobre mulheres curdas, o que envolve pontos de vista, estereótipos e relações com a identidade. Tal complementação dos autores acontece a partir do momento em que Hall define a cultura nacional como "uma das principais fontes de identidade" (2005, p. 47) e explica que o sujeito, ao nomear-se francês, alemão ou brasileiro, não se refere somente à localização geográfica no mapa-múndi, mas a uma série de significados que estabelecem o que representa ser francês, alemão ou brasileiro.

Deste modo, Woodward (2000) aborda a identidade como um ponto de comparação entre culturas. Para a autora, a identidade sérvia, por exemplo, não existe sem a croata, já que "o contraste entre uma e outra cultura (e dentro desta encontramse hábitos, valores, consumos e demais particularidades) é um dos elementos que permitem a distinção entre o que o sujeito é ou não é” (MIRANDA, 2018b, p. 16). A partir de tal contraste, é possível estabelecer um pertencimento a determinado modelo de identidade pelo fato de definir-se e até mesmo existir em relação a outra.

Embora a cultura nacional seja construída por símbolos e representações que a diferenciam de outras culturas nacionais e os sujeitos estejam incluídos nisso (ainda que possuam suas particularidades, se encaixam em uma definição maior que envolve o Estado-Nação em que se encontram), também é válido pontuar que o fenômeno da globalização rompe com a definição clássica de nação. Além do encurtamento das distâncias (espaço) e da novidade da agilidade em diversos processos (tempo), segundo Hall (2005), também se encontram no novo cenário: 
(...) a desintegração das identidades nacionais devido à homogeneização cultural que ascende mundialmente; o reforço de identidades nacionais e locais que resistem a este fenômeno, muitas vezes em um contexto de racismo cultural, como ocorre em países europeus que são alvo de imigrações diversas e tentam reforçar suas identidades tradicionais perante as "novas", vistas como ameaças; e o declínio das identidades nacionais, ao mesmo tempo em que novas identidades híbridas as substituem (MIRANDA, 2018b, p. 16).

A partir disso, pontua-se que a globalização tem gerado modificações que resultam em uma conexão mais direta entre diversos países, antes vistos como tão distantes, de forma que um acontecimento "local" ou "nacional" pode afetar outras regiões como nunca ocorrido.

Serge Moscovici (2003), alinhado a Hall (2005) e Woodward (2000), define que as comunidades às quais os indivíduos pertencem determinam a forma de tais sujeitos reagirem às mais diversas circunstâncias. Esta predefinição é denominada representação social e, devido a tal fenômeno, as pessoas pertencentes a certa cultura dificilmente estarão livres das visões de mundo já estabelecidas, o que Moscovici (2003) define como uma força irresistível ao ser.

Portanto, ao se deparar com acontecimentos provenientes de outras regiões e culturas que, até então, não lhe eram conhecidos (ou assim são, porém, de modo superficial), o sujeito tende a classificar tal assunto em questão de acordo com as visões de mundo que assimilou ao longo de sua experiência. Muitas vezes, ele encaixa algo complexo e repleto de variáveis em uma visão genérica e simplista, "sob pena de não ser compreendido, nem decodificado" (MOSCOVICI, 2003, p. 34), encaixando tal objeto de discussão, por exemplo, em um estereótipo.

Moscovici afirma que este mecanismo a respeito das representações sociais faz “com que o indivíduo seja orientado ou 'cegado' pelas mesmas” (2003, p. 30). Afinal, com a generalização de objetos, fatos e pessoas, "toda informação que chega num determinado sujeito passou, antes, por adaptações decorrentes de representações sociais sobre tudo: percepções, opiniões e vidas por meio de palavras, imagens e ideias" (MIRANDA, 2018a, p. 7), o que torna as experiências, de fato, mais subjetivas do que reais. E isso se desenvolve de maneira consciente ou não, porém, de todo modo, involuntariamente. "Nós vemos apenas o que as convenções subjacentes nos permitem ver e permanecemos inconscientes (delas)” (MOSCOVICI, 2003, p. 35). 
Tal como as representações sociais de Moscovici (2003), os estereótipos, segundo Maria Baccega (1998), "interferem na nossa percepção da realidade, levandonos a 'ver' de um modo pré-construído pela cultura e transmitido pela linguagem" (BACCEGA, 1998, p. 2).

O indivíduo, orientado pelos estereótipos e representações sociais previamente estabelecidos, forma as suas próprias percepções em relação a um determinado objeto, assunto ou acontecimento. Porém, Baccega (1998, p. 3) afirma que mesmo quando se observa diretamente o fato, ou quando o sujeito participa dele, ele viverá ou irá relatálo de acordo com um ponto de vista estruturado predominantemente pela linguagem, que transporta os conceitos e os estereótipos. E desta maneira: “(..) acabamos por dividir os fatos em dois grandes blocos: aqueles considerados 'normais' em nossa cultura, ou aqueles considerados “estranhos”' (1998, p. 3).

E sobre os fatos ocorridos além “do nosso pequeno universo”, Baccega explica que "na ampliação desse universo, os meios de comunicação exercem um importante papel - através de relatos". E que "todo relato vem impregnado dos valores e estereótipos da cultura de quem relata”.

Ecléa Bosi (2003, p. 115) complementa tal definição, explicando que "não presenciamos a maior parte dos fatos sobre os quais conversamos" e que apenas "conhecemos algumas pessoas, algumas coisas, alguns pedaços de paisagens, de ruas, alguns livros”. Deste modo, o que não se conhece, "confia-se nas pessoas que viveram e presenciaram esses fatos, e o pensamento e o discurso quotidiano se alimentam dessa confiança social” (BOSI, 2003, p. 115), o que, claramente, gera distorções de pontos de vista. Lippmann (1970) também discorre sobre o relato, afirmando que este é “(...) O produto conjunto do conhecedor e do conhecido no qual o papel do observador é sempre seletivo e geralmente criativo. Os fatos que vemos dependem da posição em que estamos colocados e dos hábitos de nossos olhos” (LIPPMANN, 1970, p. 150).

Inclusive, Bosi afirma que "o estereótipo nos é transmitido com tal força e autoridade que pode parecer um fato biológico" (2003, p. 117), quando, na realidade, ele é uma representação social, estabelecida pela cultura por meio de uma força irresistível ao ser, como visto em Hall (2005), Woodward (2000) e Moscovici (2003).

Deste modo, aqui se encaixa, por exemplo, o estereótipo acerca dos personagens e configurações dos filmes de guerra: quase sempre os personagens são homens, representados a partir de valores como virilidade, bravura e força, até mesmo de maneira exacerbada para caracterizar o personagem. Já as mulheres, comumente 
mostradas como as que esperam os seus maridos regressarem dos conflitos, ocupandose com os serviços domésticos e a organização do lar (quando muito, responsáveis pelas fabricações de equipamentos bélicos ou como enfermeiras, prontas para auxiliar na recuperação dos soldados), nunca representadas como participantes diretas de tais guerras, como se isso não fosse possível acontecer.

Entretanto, Filhas do Sol apresenta uma quebra de estereótipo nesse sentido, já que o protagonismo dos conflitos, na obra, se dá não só por meio da figura feminina, mas de todo o seu universo e outros "valores": relações com a família, sobretudo a maternidade (ponto enfático no filme), cooperação entre mulheres, outro perfil de personalidade dos personagens, apresentando características como sensibilidade e força simultaneamente (e não mais a ideia do homem viril), além das problemáticas arraigadas especialmente ao gênero, como a violência e a escravização sexual no cenário apresentado. Todas essas questões são representadas por meio da linguagem e simbolismos melodramáticos do filme, da narrativa à trilha sonora de um cinema comercial.

Outro estereótipo a ser discutido a partir do filme é o de homogeneização da cultura do Oriente Médio, sobretudo em relação aos grupos fundamentalistas. Em Filhas do Sol, diferenciam-se lutas e grupos armados: nem todos são de fundamentalistas islâmicos, bem como nem todo muçulmano é fundamentalista (questão exposta em diálogos do filme), sendo o islamismo até mesmo uma religião de guerrilheiros que combatem o extremismo de certas organizações.

O cinema pode desenvolver o papel que vai além da ficção dentro de todos esses processos citados. Lippman afirma, sobre a influência da obra cinematográfica: "não pode haver dúvida de que o cinema esteja construindo constantemente imagens que são, depois, evocadas pelas palavras que as pessoas leem nos jornais” (LIPPMANN, 1970, p. 157).

Portanto, os conceitos abordados se convergem com a obra Filhas do Sol, a partir do momento em que a diretora Eva Husson é europeia e desenvolve um filme sobre uma região e um povo do Oriente Médio. Há uma relação direta entre o filme e a reflexão sobre perpetuação de discursos (ou não), viés orientalista e representações sociais acerca da cultura e da identidade do outro.

Além disso, também há a questão do estereótipo de personagens em filmes de guerra e é notável que, embora de origem diferente daquela retratada em sua obra, o fato de a diretora de um filme sobre mulheres também ser uma mulher (ainda que 
ocidental, fator relevante para a geração de estereótipos), produz um efeito diverso do que poderia ser ao contar com um diretor do sexo masculino.

\section{Melodrama, fronteira e fabulação em Filhas do Sol}

O título da obra dirigida por Eva Husson, Filhas do Sol, remete a um batalhão formado exclusivamente por mulheres e que opera na guerra que assola o território curdo. O filme narra o encontro entre duas personagens: Bahar, líder do pelotão, e Mathilde, uma jornalista francesa. Mathilde está acompanhando o batalhão durante $o$ ataque à cidade de Gordyene, local onde Bahar foi capturada no passado. O contato entre as duas personagens acaba mudando significativamente a vida de ambas.

Logo no início do longa-metragem, é dada a seguinte informação: "baseado em fatos do Curdistão iraquiano entre 3 de agosto de 2014 e 13 de novembro de 2015". A explicação continua:

Em 3 de agosto de 2014, ISIS invadiu o Monte Sinjar: o genocídio Yazidi. Em 24 horas, 500 mil civis escaparam. O resto foi morto ou capturado. A resistência era composta por yazidis, guerrilhas curdas e um exército oficial. Nomes de pessoas, lugares, facções e datas foram alterados.

O filme se inicia em uma cena de Bahar (guerrilheira curda) deitada, desacordada, repleta de poeira, em meio a escombros. Bahar desperta aos poucos e torna-se cada vez mais lúcida. Entende-se que houve uma explosão, da qual ela sobreviveu. Logo em seguida há fumaça em um céu azul e outra personagem aparece: é Mathilde (interpretada por Emmanuelle Bercot), a jornalista francesa com um tapaolho (que remete claramente à jornalista Marie Colvin5). Aparentemente, Mathilde sonhava com a fumaça e acorda assustada.

As falas que se seguem são provenientes de pensamentos da jornalista (inclusive, nota-se que o filme se desenvolve em sua perspectiva testemunhal): "11 de novembro, estou presa na fronteira turca há uma semana”. Em seguida, ela explica os problemas dessa situação e se queixa sobre não estar em seu local de trabalho, além da necessidade de se encontrar com o seu fixer. Segundo Patrícia Campos Mello:

\footnotetext{
5 Mais à frente na trama, a personagem Mathilde explica que perdeu o olho esquerdo durante uma explosão em Homs (Síria), onde um estilhaço de granada atingiu o órgão. Tal acontecimento ocorreu de fato com a jornalista nova-iorquina Marie Colvin, o que leva a se concluir que Mathilde faz referência ao ícone do jornalismo.
} 
O fixer é a figura mais importante de qualquer cobertura jornalística internacional. É uma pessoa local, que atua como tradutor, às vezes motorista, mas principalmente termômetro cultural. É uma pessoa que conhece a política do lugar, as pessoas, as motivações de cada um, e nos ajuda a entender o contexto de cada situação. (...) Sem ele, o jornalista não passa de um turista mal informado (2017, p. 27).

\section{Figuras 2 e 3: Reflexão que faz analogia entre as duas personagens}
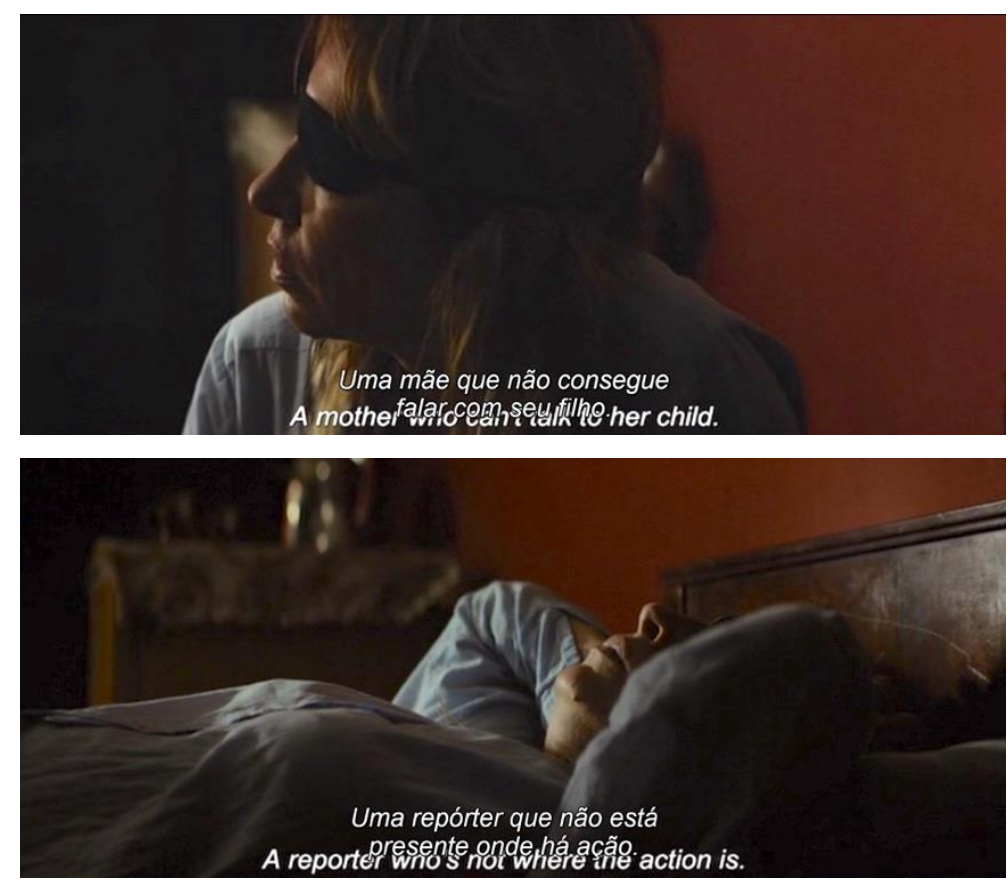

Fonte: fotogramas de Filhas do Sol (2021).

É válido pontuar que, não à toa, Mathilde participa como uma personagem adicional no filme: a diretora francesa, Eva Husson, já confessou em entrevistas que inserir a correspondente de guerra francesa foi uma forma de garantir o financiamento da produção. Bordwell (2013), ao conceituar a análise fílmica, leva em conta fatores externos que podem motivar ou interferir na narrativa dos filmes, como visto, nesse quesito, em Filhas do Sol: uma questão prática e de viabilização da obra levou a diretora a criar uma personagem exclusiva para tal.

Ainda nos primeiros minutos da produção, Bahar responde à pergunta da jornalista sobre sua tatuagem com os nomes de seu filho e de seu marido (este morto pelo Estado Islâmico). Ao contrário do que muitos estariam habituados a considerar, não é puramente uma homenagem, mas algo permeado por uma questão prática do cenário vivido: uma necessidade de "identificação" física caso aconteça algo com Bahar, sobretudo pela atuação do Estado Islâmico (a personagem indica que seria em 
cativeiro e não em combate, principalmente pelo fato de todo o seu grupo ser formado por ex-prisioneiras do Daesh).

Figuras 4 a 9: Sequência que evidencia as semelhanças das personagens em relação às marcas dos conflitos impressas em seus corpos
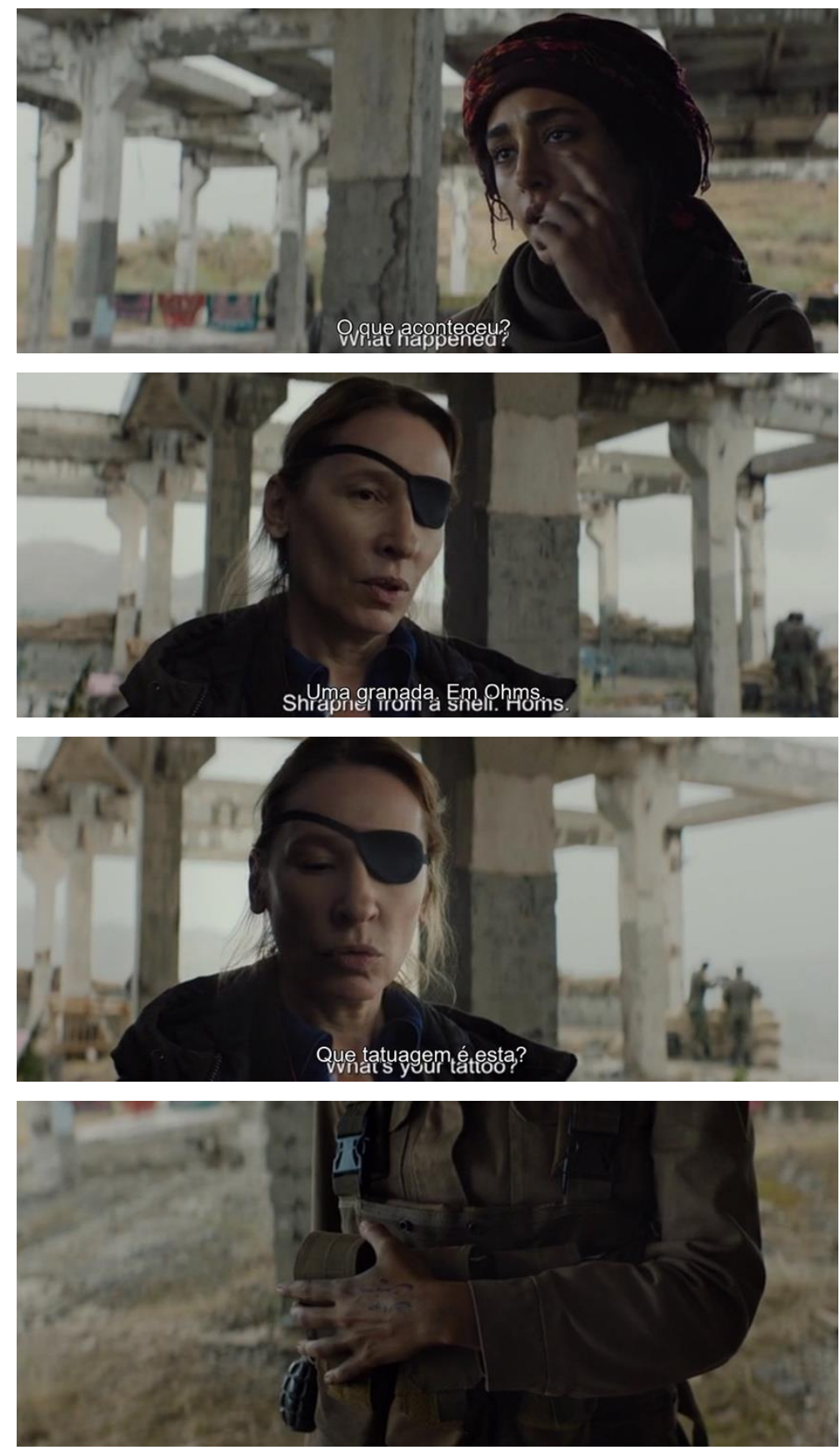

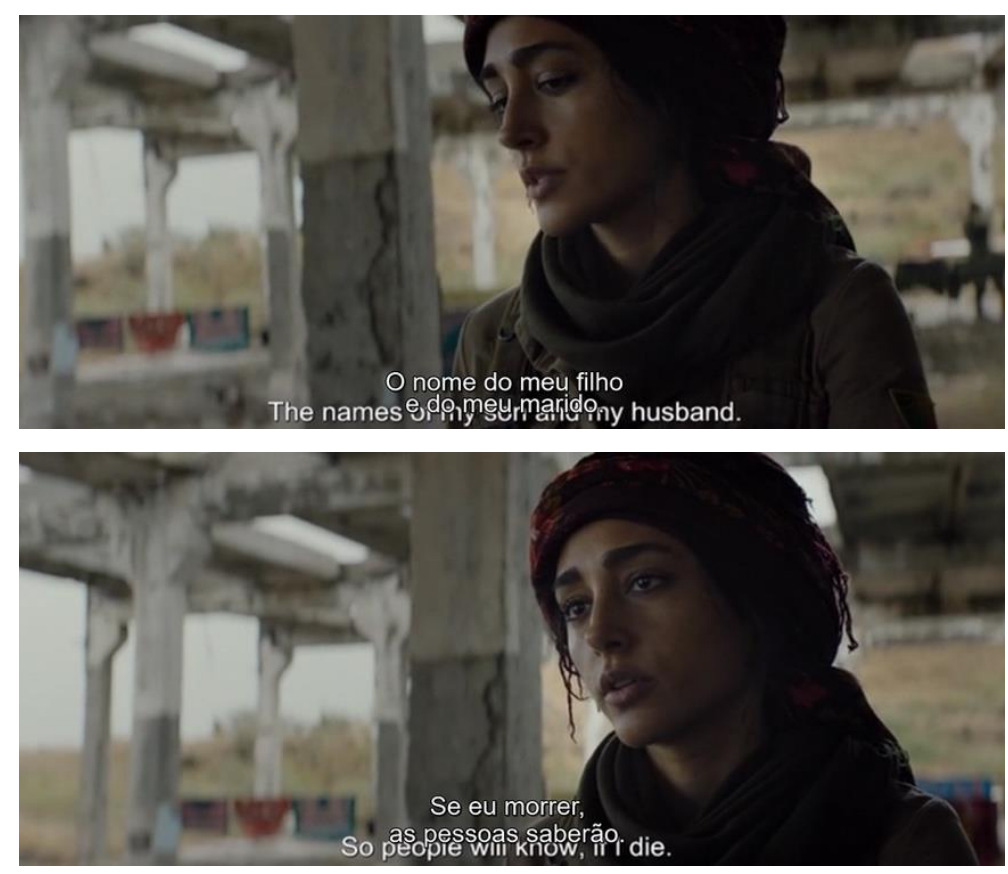

Fonte: fotogramas de Filhas do Sol (2021).

Um dos planos mais expressivos da obra vem em seguida: a câmera lenta se fecha no rosto de Bahar e faz o registro que também vem a ser o cartaz de divulgação do filme. A expressão da personagem é de profunda introspecção em suas memórias e sofrimento interno, e é notável que a duração de tal passagem, os ângulos e modos como foi construída a cena enfatiza o seu viés psicológico.

\section{Figura 10: Bahar em momento de flashback, mergulhada psicologicamente em} suas memórias

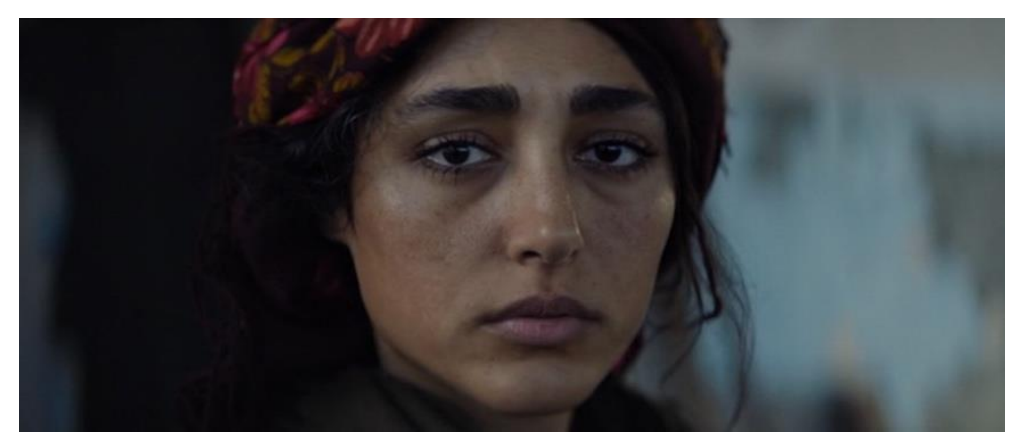

Fonte: fotograma de Filhas do Sol (2021).

Neste ponto, chamemos atenção para o gênero em que Filhas do Sol se encaixa. Mariana Baltar, pesquisadora especialista em melodrama, (BALTAR, s/p, grifo nosso) afirma que são dois os elementos derivativos importantes para a articulação melodramática por excelência: "a simbolização exacerbada, sobretudo através de 
metáforas pautadas por uma obviedade, e o elemento da antecipação”. A primeira apresenta os elementos-chave da narrativa, por meio "de uma imagem ou objeto" (BALTAR, s/p), de forma a expressar visualmente tais dicotomias (tal como as simbologias e analogias feitas entre as personagens Bahar e Mathilde ao longo do filme). A segunda expressão "possui um vínculo com o suspense e é um dos mecanismos que produzem as lágrimas no melodrama", que se constrói com "pistas que antecipam o desfecho da narrativa e mobilizam a empatia do público" (BALTAR, $\mathrm{s} / \mathrm{p})$.

Além dos dois fatores citados, a autora também destaca o conceito de obviedade, que "é estratégico para que o público possa compreender de imediato as polaridades moralizantes que distinguem o bem do mal na narrativa melodramática" (BALTAR, $\mathrm{s} / \mathrm{p}$ ). Tal resultado é atingido por meio do uso de "metáforas exacerbadas e óbvias" (BALTAR, s/p), de forma que, no caso da obra em questão, o público logo se vê polarizado entre o grupo feminino, que inclui as combatentes curdas e a jornalista, e o Estado Islâmico (indicado, de forma clara, como "vilão").

O melodrama está vinculado com o estabelecimento de uma relação emocional (sentimental e sensorial) ativada pelo excesso através da exacerbação da retórica, da gestualidade, do ilusionismo, da música, de uma mise en scène articulados em uma prerrogativa de mostrar e falar tudo, reiterando sempre os valores de virtude e bondade através de ações que se desenrolam expressivamente. O modo de excesso está diretamente ligado a uma exacerbação da "cena", onde a materialidade da voz e das palavras dos atores, cada objeto do cenário e do figurino, da luz e dos cortes e movimentos (no palco e na câmera) são pautados por uma grandiloquência e por um sentido metafórico da caracterização do personagem. Precisamos "de pronto" enxergar o bem e o mal, localizar na superfície da cena e das ações as polaridades moralizantes que se encenam no repertório estético e temático do melodrama (BALTAR, s/p).

Curiosamente, segundo Peter Brooks (apud Baltar, 2005, grifo nosso), o melodrama cumpre um papel de "pedagogia moralizadora da modernidade ocidental, argumentando que tal imaginação e pedagogia foram fundamentais no conturbado contexto das revoluções burguesas", o que se leva a refletir que, por isso, a diretora optou pelo uso de tal linguagem em seu filme.

Ainda sobre Filhas do Sol: variando entre tons de amarelo, laranja e vermelho, tais representações condizem não só com a própria bandeira do Curdistão iraquiano, que traz um sol de 21 raios ao centro (pois o astro é um elemento importante na cultura 
curda e simboliza questões religiosas, sendo ainda mais evidente a escolha por tais cores, além do título Filhas do $\mathrm{Sol}$ ), mas a uma estética já vista em filmes como Apocalypse Now, do diretor Francis Ford Coppola, cujo tema assemelha-se (conflitos armados).

A partir deste momento, a sequência que se dá na narrativa fílmica parece indicar a semelhança entre a jornalista francesa, Mathilde, e Bahar, a comandante da YPJ, como mulheres. Após Bahar falar sobre sua família e de serem mostradas suas diversas memórias do marido e do filho, segue-se para uma cena em que Mathilde lembra também de sua família, via imagens do telefone celular.

A essa altura do filme, que sequer passou dos primeiros vinte minutos, já se nota fortemente a relação de analogia entre ambas, tanto pelos diálogos quanto pelas escolhas de montagem das cenas: mesmo que Bahar seja uma combatente curda, de formação social e cultural extremamente diversa de Mathilde, e que a jornalista seja uma mulher branca, francesa, de formação ocidental que, inclusive, direta ou indiretamente oprime a etnia curda como sociedade orientalista, ambas são mulheres. Tal relação é reforçada por diálogos entre as duas e por mostrar que ambas são mães e possuem preocupações em comum, sendo a maternidade uma questão enfatizada reiteradamente no filme (inclusive em uma cena de trabalho de parto em meio a uma fuga do Daesh, cuja trilha sonora enfatiza ainda mais o sofrimento deste momento).

A própria personagem Bahar define tal questão feminina quando comenta sobre ser alvo do Estado Islâmico como escrava sexual, em que diz para Mathilde que, em qualquer lugar ou cultura, basta ser mulher (para estar na mira do Daesh, da escravização sexual ou até mesmo para sofrer diversas adversidades justamente por conta de seu gênero), embora possuam diversas diferenças de formação.

Outro ponto interessante da produção é que, em diversos momentos, no enquadramento do filme, é feita uma analogia entre o equipamento bélico e o equipamento de fotografia da jornalista, de forma que fique clara a ideia: Bahar está munida de armas para lutar, enquanto Mathilde está munida de sua câmera para produzir informação. A primeira sugestão se dá quando Bahar empunha sua arma ao mesmo tempo em que Mathilde empunha a sua câmera, construindo uma analogia visual por meio de tal composição no quadro. Em outro momento, ambas dialogam sobre a importância do relato. Bahar é quem manifesta o desejo de que Mathilde as acompanhe, pontuando a necessidade de seu testemunho diante dos fatos para relatálos depois. Mais à frente no filme, Bahar explica a Mathilde a importância de que exista 
alguém para contar a história e levá-la para as pessoas lá fora conhecerem a verdade. A narrativa transmite um conceito próximo à ideia de que saber é poder ou o conhecimento também é uma arma.

Sendo assim, sobretudo pela questão curda, o filme apresenta imagens que produzem "outros regimes de visibilidade e legibilidade dos povos e de suas existências", segundo Angela Marques (2020, p. 243), que se inspira nas ideias de DidiHuberman e Rancière e apresenta as nuances de pensamentos entre ambos. Tal possibilidade define-se pela reflexão sobre o trabalho realizado pelas imagens, "produzindo memória e imaginário; sintoma e intervalo; cena e montagem” (2020, p. 243), o que remete ao conceito de fabulação, abordado por Marques.

A ficção cria um tecido sensível novo, na qual sujeitos até então invisibilizados tomam parte e aparecem registrados em uma história comum, contrariando uma hierarquia e afirmando cenas ficcionais e polêmicas que remontam o real consensuado, construindo momentos nos quais a indecisão para julgar suplanta a certeza das verdades controladas (MARQUES, 2020, p. 250).

Ainda segundo a autora, que a todo momento compara as reflexões de DidiHuberman e Rancière, "a ideia de fabulação e sonho é comum ao modo como os autores em questão caracterizam o trabalho das imagens" (2020, p. 259). Para Marques (2020, p. 259), "ambos, cada um a seu modo, nos alertam para como as potências da legibilidade promovida pelas imagens podem tornar-nos sensíveis à dialética das aparências, das aparições, dos gestos e dos olhares”. Entretanto, destaquemos o conceito defendido por Didi-Huberman, que define a função das imagens em "nos tornar sensíveis à vida dos povos", algo que se encaixa à obra e ao tema em questão. 
Figura 11: imagem de divulgação do filme que faz analogia entre a jornalista com a câmera e a guerrilheira com a arma, editada em cores quentes

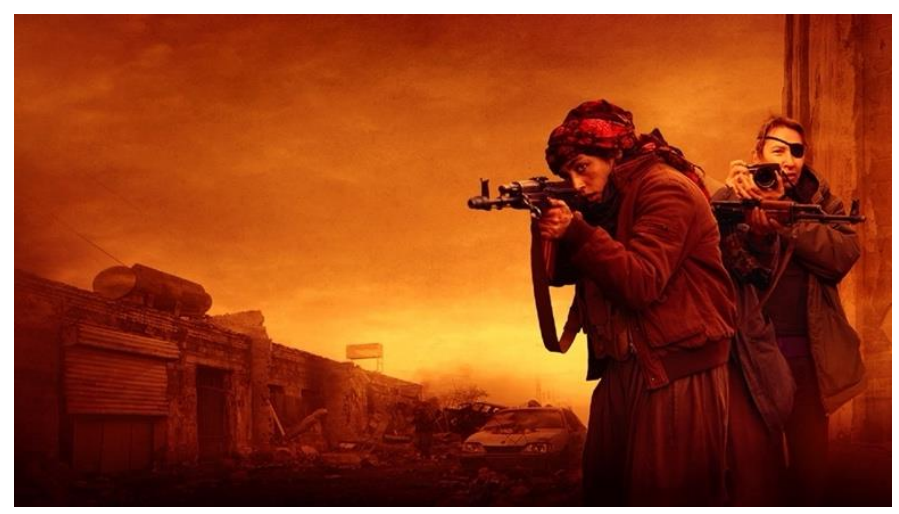

Fonte: Coadjuvante (médium, 2020) ${ }^{6}$.

Quando Mathilde expõe o seu ponto de vista e sentimentos sobre sua profissão, é válido dizer que a sensação de "inutilidade" da personagem representa um cenário de desvalorização da profissão jornalística enquanto categoria, e não meramente pessoal, cujos efeitos recaem sobretudo em quem a exerce, apesar da sociedade como um todo ser prejudicada.

Ao final da obra, após os combates e após se despedir de Bahar e de todas as soldadas curdas, Mathilde segue de volta para seu país. Percorre-se por alguns momentos o trecho em que a jornalista está no carro, em uma estrada, refletindo sobre todas as experiências diante da paisagem de montanhas (ambientada coerentemente, de acordo com a definição de povos das montanhas, dos curdos), que se esvai pouco a pouco.

Nessa cena final o espectador se vê diante de um relato significativo da jornalista, que até então, mesmo em diálogos com Bahar e as combatentes curdas, sempre manteve um papel muito mais testemunhal do que opinativo: por quase 3 minutos, Mathilde monologa sobre a luta de Bahar, sua força, a força dessas mulheres enquanto grupo organizado (sobretudo com tantas ameaças violentas contra si, pelo simples fato de existirem) e define que tudo o que passaram nas mãos do Daesh é incompreensível, relembrando que em uma só noite 7 mil mulheres curdas foram capturadas pela organização e feitas de escravas sexuais, inclusive crianças. A reflexão é finalizada com a lembrança de uma das canções populares curdas que enaltece a luta feminina, além do comentário de que nunca foi designada para um batalhão feminino

\footnotetext{
${ }^{6}$ Disponível em: https://medium.com/coadjuvante/o-filme-filhas-do-sol-dbc33e8dd13.
} 
e, ao ter esse contato diário, teve despertada não só a sua fragilidade humana, mas a lembrança do próprio motivo que a fez escolher a profissão de jornalista.

Mathilde relata que a sua verdade sobre as mulheres curdas é uma história de resistência, luta e unidade: "E eu, Mathilde H., tremo ao ouvir suas vozes. Uma música performática. Uma música poderosa. Uma música ancestral. Uma música que nos faz levantar. Uma esperança que desafia a condição humana”, finaliza, reforçando o tom melodramático do filme.

\section{Considerações finais}

O filme Filhas do Sol abrange complexidades exclusivas da situação curda em sua narrativa, como a expressão de um feminismo particular empreendido pelas mulheres curdas, baseado em formas coletivas de vida e sistemas políticos distintos daqueles que são comuns às sociedades capitalistas e ocidentais. Isso confere vínculo com o mundo histórico e proximidade do filme com o seu público-alvo, já que a obra adota elementos expressivos como a trilha sonora ininterrupta e magnificente, simbologias visuais e físicas, sequências de cenas com diálogos que conectam histórias e questões psicológicas entre as protagonistas, além de flashbacks e passagens em câmera lenta.

Embora seja uma obra construída nos moldes do cinema comercial, de dimensão ficcional e melodramática, com um apelo estético direcionado a um grande público, Filhas do Sol se configura como uma das poucas obras audiovisuais que trazem à tona a questão das mulheres curdas ao espectador ocidental, em uma linguagem que lhe é comum, sobretudo o europeu.

Além de enfatizar as dificuldades e lutas diárias das mulheres curdas, de um modo geral, a obra apresenta um importante elo entre as duas protagonistas calcado na maternidade e também na analogia entre os corpos carregados de marcas físicas provenientes dos conflitos armados que ambas as personagens enfrentaram no passado. Desta forma, o filme atinge um efeito crucial para a representação do panorama do conflito curdo ao aliar fatos baseados em experiências pessoais reais com questões ficcionais - em uma dimensão potente de fabulação - das personagens, cujas próprias vivências e dramas pessoais se mostram diretamente ligados a questões sociais e políticas, com foco específico na questão feminina.

O filme opera, portanto, em uma construção estética e narrativa que valoriza as situações dramáticas de sofrimento pessoal das personagens relacionando-as ao papel 
sociopolítico que muitas mulheres desempenham no seio do conflito curdo. Sua importância para a discussão proposta neste artigo não se restringe puramente em seu conceito estético e artístico, mas também no efeito que o filme produz a partir de suas escolhas de representação, sendo uma importante contribuição para as reflexões tanto sobre a situação curda, quanto para a relação Ocidente/Oriente e a ideia de orientalismo.

\section{Referências}

AMIN, Samir. O eurocentrismo: crítica de uma ideologia. São Paulo: Lavrapalavra, 2021.

APOCALYPSE now. Direção: Francis Ford Coppola. Produção: Francis Ford Coppola, Gray Frederickson, Fred Ross. 1979. DVD. 153 min. son., color.

BACCEGA, Maria Aparecida. O estereótipo e as diversidades. In: Comunicação \& Educação, n. 13, dez. 1998, pp. 7-14.

BALTAR, Mariana. Metáforas à flor da pele: Os excessivos símbolos que antecipam nossa comoção. In: Contracampo - Revista de Cinema, v. 71, p. 71, 2005. Disponível em: http://www.contracampo.com.br/71/metaforas.htm. Acesso em 13 de dezembro de 2021.

BBC. Quem são os curdos e por que são atacados pela Turquia. 12 de outubro de 2019. Disponível em: https://www.bbc.com/portuguese/internacional-50012988. Acesso em: 13 de dezembro de 2021.

BORDWELL, David; THOMPSON, Kristin. A arte do cinema: uma introdução. Campinas/São Paulo: Editora da Unicamp/Edusp, 2013.

BOSI, Ecléa. O tempo vivo da memória: ensaios de psicologia social. São Paulo: Ateliê Editorial, 2003.

COMITÊ de Solidariedade à Resistência Popular Curda de São Paulo. Glossário. In: DIRIK, Dilar et al. A revolução ignorada: Liberação da mulher, democracia direta e pluralismo radical no Oriente Médio. São Paulo: Autonomia Literária, 2017, pp. 8-12.

DIRIK, Dilar. Apresentação: Construindo uma democracia radical sem Estado. In: DIRIK, Dilar et al. A revolução ignorada: Liberação da mulher, democracia direta e pluralismo radical no Oriente Médio. São Paulo: Autonomia Literária, 2017, pp. 16-27.

FIGUEIREDO, Felipe. Os curdos. Xadrez Verbal, 12 ago. 2014. Disponível em: https://youtu.be/hDD_Lyb_M8U. Acesso em 13 de dezembro de 2021.

FILHAS do Sol. Direção: Eva Husson. Produção: Didar Domehri. Telecine Play (streaming). 109 min. Acesso em 28 de junho de 2020.

FOUCAULT, Michel. A ordem do discurso. São Paulo: Edições Loyola, 1996.

HALL, Stuart. A identidade cultural na pós-modernidade. São Paulo: DP\&A, 2005. 
LIPPMANN, Walter. Estereótipos. In: STEINBERG, Charles S. (Org.). Meios de comunicação de massa. São Paulo: Cultrix, 1970, pp. 149-159.

LOBATO, José Augusto Mendes. Demarcando fronteiras na tela da TV: as representações de alteridade na cobertura jornalística internacional. São Paulo: Rumores, 2015.

MARQUES, Ângela Cristina Salgueiro; MARTINO, Luis Mauro Sá. Fabular imagens intervalares e montar imagens sobreviventes: aproximações e diferenças entre os métodos de Rancière e Didi-Huberman. Logos (Rio de Janeiro/Online), v. 27, p. 242-261, 2020. Disponível em: https://www.e-

publicacoes.uerj.br/index.php/logos/article/view/49270/33920. Acesso em 13 de dezembro de 2021.

MELLO, Patrícia Campos. Lua de mel em Kobane: uma história de amor improvável em meio à barbárie da Guerra da Síria. São Paulo: Companhia das Letras, 2017.

MIRANDA, Juliana Santoros. Consumo ou vivência de alteridade? O jornalismo internacional e a cobertura de conflitos na perspectiva de correspondentes e editores. Anais do Congresso Internacional Comunicação e Consumo 2018, ESPM. São Paulo, 2018a. Disponível em: http://anais-comunicon2018.espm.br/encontroGrad.aspx. Acesso em 13 de dezembro de 2021.

MIRANDA, Juliana Santoros. O jornalismo internacional e os processos de edição: um estudo sobre a cobertura de conflitos no Oriente Médio e norte da África. Monografia de conclusão de curso em Comunicação Social (Jornalismo) apresentada à Universidade Anhembi Morumbi. 103 f. São Paulo, 2018b.

MOSCOVICI, Serge. Representações sociais. Petrópolis: Vozes, 2003.

NAVARRO, Roberto. Qual é o maior povo sem país? Superinteressante, 4 jul. 2018. Disponível em: https://super.abril.com.br/mundo-estranho/qual-e-o-maior-povo-sem-pais. Acesso em 13 de dezembro de 2021.

ORLANDI, Eni Puccinelli. Terra à Vista: Discurso do confronto - Velho e Novo Mundo. São Paulo: Cortez Editora, 1990.

PESSUTO, Kelen. Made in Kurdistan: Etnoficção, infância e resistência no cinema curdo de Bahman Ghobadi. 2017. $401 \mathrm{f}$. Tese (Doutorado em Antropologia Social) - Faculdade de Filosofia, Letras e Ciências Humanas, Universidade de São Paulo, São Paulo, 2017.

SAID, Edward W. Orientalismo: O Oriente como invenção do Ocidente. São Paulo: Companhia das Letras, 1990.

SANTOS, Rafael José dos. O 'étnico' e o 'exótico': notas sobre a representação ocidental da alteridade. Rosa dos Ventos, n. 5, out-dez 2013, pp. 635-643.

VÁZQUEZ, Jordi. Pinceladas sobre o Curdistão. In: DIRIK, Dilar et al. A revolução ignorada: Liberação da mulher, democracia direta e pluralismo radical no Oriente Médio. São Paulo: Autonomia Literária, 2017, pp. 35-50.

WOODWARD, Kathryn. Identidade e diferença: uma introdução teórica e conceitual. In: SILVA, Tomaz. Identidade e diferença: a perspectiva dos Estudos Culturais. Petrópolis: Vozes, 2000. 
ŽIŽEK, Slavoj. Os curdos são a nação democrática mais progressista do Oriente Médio. Lavrapalavra, 28 out. 2015. Tradução de Leo Griz Carvalheira. Disponível em: https://lavrapalavra.com/2015/10/28/slavoj-zizek-os-curdos-sao-a-nacao-democraticamais-progressista-do-oriente-medio/. Acesso em 13 de dezembro de 2021.

\footnotetext{
Este é um ARTIGO publicado em acesso aberto (Open Access) sob a licença Creative Commons Attribution, que permite uso, distribuição e reprodução em qualquer meio, sem restrições, desde que o trabalho original seja corretamente citado.
} 